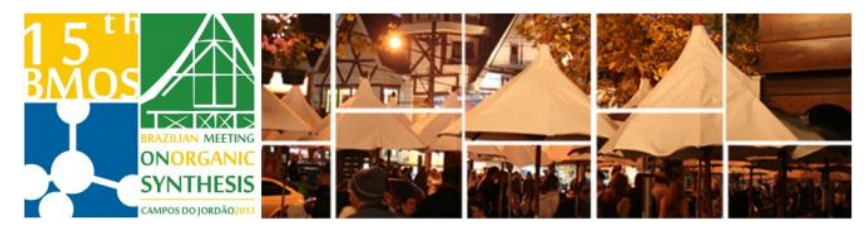

\title{
Organoselenium functionalized nitrogen heterocycles: a proposition for new antimalarials.
}

\author{
Gabriela D. da Silva, ${ }^{1 *}$ Piero Bagnaresi ${ }^{2}$ and Rodrigo L. O. R. Cunha ${ }^{1}$ \\ ${ }^{1}$ Laboratório de Biologia Química, Centro de Ciências Naturais e Humanas, UFABC; \\ ${ }^{2}$ Biologia Celular e Bioquimica de Infecções Parasitárias, Departamento de Biociências, UNIFESP \\ *silva.gdias@gmail.com
}

Keywords: $S_{N} A r$, pyridines, quinolones

\section{INTRODUCTION}

Every year, approximately 250 millions of peoples are diagnosed with malaria. ${ }^{1}$ The synthesis of hybrid compounds aims to maximize the performance of drugs. ${ }^{2}$ Contemplating two distinct properties, the similarity with chloroquine and moiety containing selenium, as an inhibitor of proteases ${ }^{3}$ involved in the life cycle of the parasite.

In this work, we realized synthesis of various hybrid compounds via nucleophilic aromatic substitution reactions between arilselenoaniline $e^{4,5}$ and diclhoroquinolines and chloropyridines.

\section{RESULTS AND DISCUSSION}

The starting aniline $\mathbf{4}$ was synthetized from diphenyl diselenide (1) through a nucleophilic aromatic substitution using 4-nitrofluorbenzene (2) leading to the selenide $\mathbf{3}$ which was reduced using tin(II) chloride (Scheme 1).

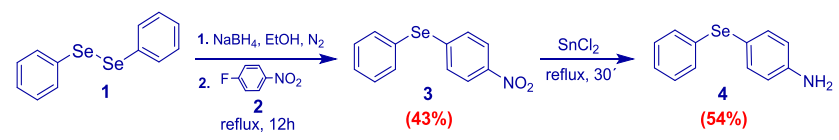

Scheme 1. Synthesis of 4-(phenylseleno)aniline (4).

The aniline $\mathbf{4}$ was used as a model nucleophile to functionalize chloro-pyridines 5a-c, 4,7dichloroquinoline (6a) and 2,8-dicloroquinoline (6b) leading to amino-substituted nitrogen heterocycles (Chart 1).

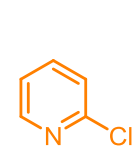

$5 a$

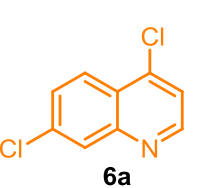

$6 a$

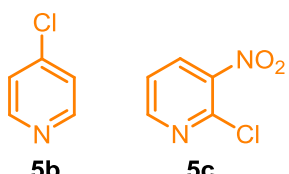

5c

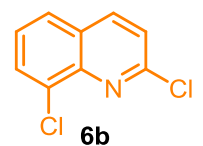

Chart 1. Structures of studied chloro-nitrogen heterocicles.

The functionalizations of heterocycles $5 a-c$ and $6 a-b$ were performed in a sealed tube using aniline (7) and the 4-(phenylseleno)aniline (4) in equimolar amounts of reagents in ethanol solution heated at $120^{\circ} \mathrm{C}$ for $2 \mathrm{~h}$ as depicted in Scheme 2. Aniline (7) was used to compare the effect of the phenylselenenyl moiety in the relative reactivity and to parallel the biological studies using malaria enzymatic and cellular models.

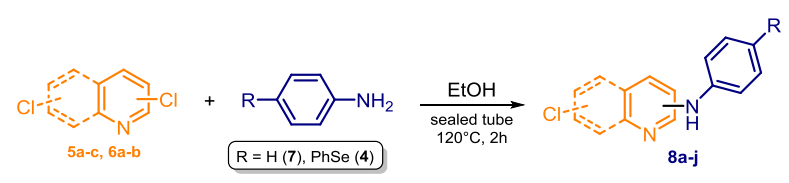

Scheme 2. General reaction for the SNAr reactions.

The reactivity of pyridines and quinolones was distinct, the former were more reactive, especially pyridine $5 \mathbf{c}$ and the latter less reactive. The difference on reactivity among $6 \mathbf{a}$ and $\mathbf{6 b}$ were remarkably distinct even with long reaction time (30h), the functionalization of $\mathbf{6 b}$ showed to be more difficult. The reaction yields varied from poor to moderate yields.

\section{CONCLUSION}

This work show that nucleophilic aromatic substitution reactions were effective on obtainment of hybrid compounds of quinolines, pyridines and organoselenides for new drugs

\section{ACKNOWLEDGEMENTS}

UFABC for scholarship, CNPq and FAPESP for financial support. And Mirela I. Sairrê, Professor Ph.D. for RMN-H ${ }^{1}$ characterization.

\section{REFERENCES}

${ }^{1}$ Parmet S, L. C. G. R. M. JAMA 2010, 304, 2084.

${ }^{2}$ Gemma, S.; et. al, S. Bioor.\& Med Chem Letters 2006. 16: p. 5384.

${ }^{3}$ Rosenthal, P. J.; Dominguez, ND. G. Blood, 1996. 87: p. 4448-4454.

${ }^{4}$ Deobald, A. M., L. R. Simon de Camargo, Tetrahedron Letters. 2010. 26: p. 3364-3367.

${ }^{5}$ Bellamy, F. D. and K. Ou Tetrahedron Letters 1984. 25(8): p. 839-842. 